\title{
THE TREATMENT OF BRONCHIAL CARCINOMA BY LOBECTOMY AND SLEEVE RESECTION OF THE MAIN BRONCHUS
}

\author{
BY \\ J. B. JOHNSTON AND P. H. JONES \\ From the Brompton Hospital and the London Chest Hospital, London, and Baguley Hospital, Manchester
}

(RECEIVED FOR PUBLICATION JULY 27, 1958)

\section{HISTORICAL INTRODUCTION}

In 1947 Price Thomas performed a bronchotomy and removed a portion of the circumference of the wall of the right main bronchus for an adenoma, performing a plastic repair of the bronchus (Price Thomas, 1956). The patient had a straightforward convalescence, with good primary union of the bronchus, and has continued to make good use of both lungs ever since. The procedure has been repeated with success on several occasions.

In 1952 he carried the idea further, in the treatment of a patient with a stricture of the main bronchus, in association with a destroyed tuberculous left upper lobe. In this case, the lower lobe was saved by resecting the stricture and anastomosing the divided ends of the main bronchus. The patient had a positive sputum at the time of operation, and subsequently developed tuberculous endobronchitis at the suture line, spreading distally, so that the pneumonectomy had to be completed. Nevertheless, it had been established that when two ends of a bronchus were sewn together they could unite in the same way as two pieces of intestine. When the operation was performed on several subsequent occasions at a time when the sputum did not contain tubercle bacilli, the post-operative course was without incident, and sleeve resection has been confirmed by numerous authors as the ideal treatment for this condition.

With the concept of resection of the entire circumference of portions of the bronchial tree followed by anastomosis established as a sound surgical procedure, it was reasonable to speculate on whether there was any place for this operation in the treatment of carcinoma of the bronchus.

It should be said at the outset that we believe that the ideal treatment at the present time for carcinoma of the lung is probably the removal of the entire organ with its associated lymphatic field. 올 The results, of the order of five-year survival in 20 to $30 \%$, reported by Churchill, Sweet, Soutter, $\frac{3}{0}$ and Scannell (1950), Price Thomas (1952), Ochsner, Ray and Acree (1954), Brock and Whytehead (1955), Bignall and Moon (1955), and Kirklin, $\overrightarrow{0}$ McDonald, Clagett, Moersch, and Gage (1955) compare well with the results of surgical treatment $O$ of carcinoma in other fields. Yet, in an increasing number of patients, the ideal cannot be attained without achieving the paradox of surgical cure in the presence of a dead patient. Most often $\mathbb{\perp}$ carcinoma of the lung is a disease of the sixth and $\overrightarrow{\vec{P}}$ seventh decades, and it is at this time that the $\frac{3}{3}$ average individual naturally begins to suffer the effects of a rapidly diminishing cardio-respiratoryo reserve. This point cannot be better illustrated than by referring to the mortality rate for pneumonectomy according to age group in Price $\underset{x}{0}$ Thomas's (1958) series. Death is considered to be due to the operation if the patient was unable 3 . to leave hospital.

TABLE I

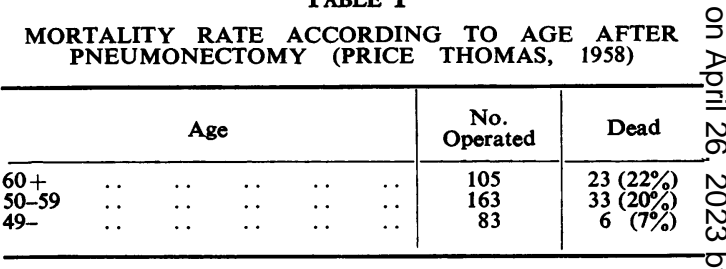

Where the tumour is peripheral, and clear ofo the lobar hilum, without metastases in the lymph nodes, it is possible to do a lobectomy in those? patients in whom pneumonectomy could not be tolerated. Unfortunately, a large proportion of carcinomas in the upper lobes can either be seen $\stackrel{\mathbb{S}}{\mathscr{S}}$ by the telescope bronchoscopically, or invade $\mathbb{Q}$ the upper lobe orifice, or have extended along the main bronchus. Lobectomy cannot meet the 
minimum requirements for the extirpation of such lesions, and it was only after the evolution of sleeve resection that anything short of a pneumonectomy could be offered to such patients.

It is also becoming well appreciated that there is a lessening of morbidity following lobectomy as compared with pneumonectomy. It contravenes surgical principles to leave a large space inside the body, for such a space is heir to infection with its consequences. In the particular case of pneumonectomy this is shown by a considerable incidence of empyema and bronchopleural fistula. But, where lobectomy has been performed, and a portion of lung is left behind to fill the space and the drainage tubes are managed skilfully, such complications are rare. From our experience it appears that the same low morbidity pertains after sleeve resection.

In 1952 Allison performed lobectomy with sleeve resection of the main bronchus and a segment of the pulmonary artery for bronchial carcinoma (Allison, 1956). This is the first instance where the operation was used in carcinoma, and the first recorded instance of resection of segments of both artery and bronchus.

\section{The Present Series}

From 1953 to the present time 98 patients in the group to be presented had some form of sleeve resection performed for carcinoma of the bronchus. In almost equal numbers they have been under the care of Sir Clement Price Thomas in London, and of one of the authors (P. H. J.) in Manchester.

Eighty-one of the patients were men and 17 were women.

Their ages covered a range from 39 to 72 , with the following distribution according to decades :

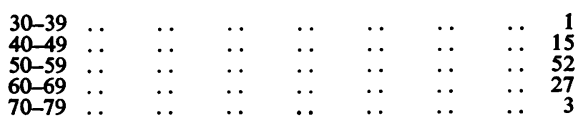

\section{Selection of Patients}

A combination of physiological and anatomical factors led to this operation being performed in any individual patient. It had been agreed before the operation that lobectomy would have been preferable to pneumonectomy in all these patients, and in many it was in fact mandatory because of depletion of the cardio-respiratory reserve. In the majority this impairment was due to a combination of chronic bronchitis and emphysema. In six patients there was contralateral tuberculosis. Two patients had carcinoma in the other lung, one concurrent, and the other had previously had part of the other lung removed. One patient had had a severe myocardial infarction previously. For these various reasons a limited resection was preferred, and in each it was necessary to perform a sleeve resection because of the anatomical situation or extent of the growth, i.e., it could either be seen within the upper lobe orifice, or had invaded the upper lobe orifice, or had extended along the main bronchus. Where an upper lobe growth projected as a polyp into the main bronchus, without involving the adjacent walls of the upper lobe bronchus or main bronchus, it was not considered necessary to perform a sleeve resection. In one patient the growth involved the carina, and it was found that, following resection of the upper lobe and main bronchus together with the carina, the most satisfactory way of dealing with the deficiency in the trachea was to implant the right middle and lower lobes. Similarly, where the growth had spread up the trachea from the tracheo-bronchial angle, it was found to be more satisfactory to implant the right middle and lower lobes than to close the tracheal defect with a flap or graft. Finally, in three patients in whom the chest wall was involved, and in two where the growth was believed to be an isolated metastasis, it was considered that the operation would be no more than palliative, and lobectomy would have been the operation of choice.

\section{TyPe OF Operation}

The particular operation performed depended on the individual circumstances found at operation, but in each case the procedure was adapted to resect as widely as possible the local lesion and its extensions.

TABLE II

TYPE OF OPERATION

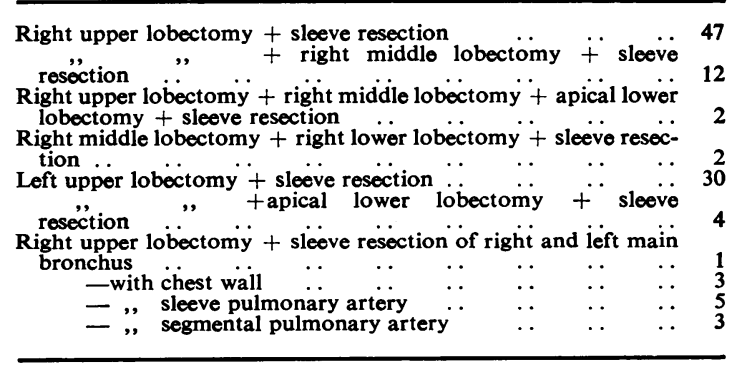

\section{TeChNiQue}

In the first instance, once the chest is opened a preliminary reconnaissance is carried out to determine whether any resection is possible. This 


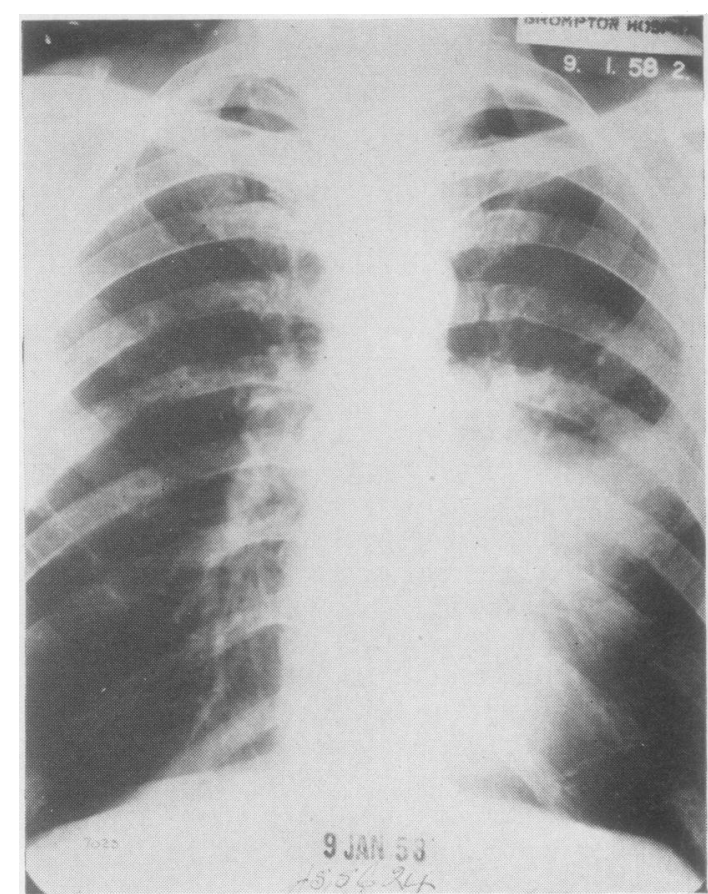

FIG. 1a.-Postero-anterior chest radiograph of a man aged 57 with adenocarcinoma of the left upper lobe, involving the main bronchus.

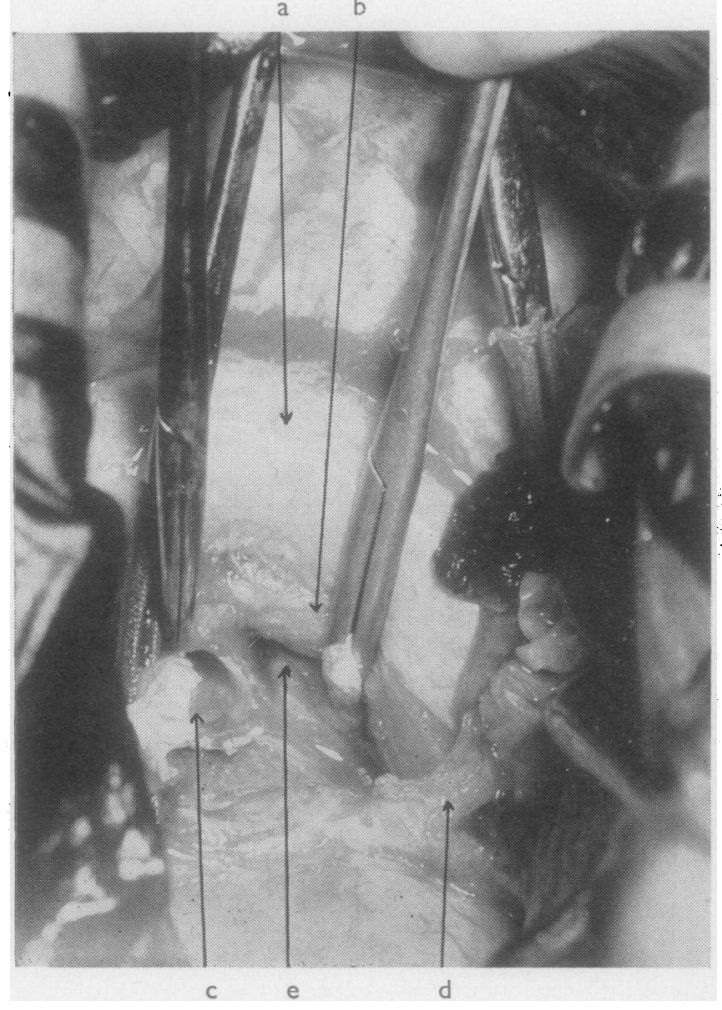

FIG. 2.-After removal of the left upper lobe and sleeves of the main bronchus and pulmonary artery. (a) Aortic arch. (b) Oesophagus. (c) Proximal bronchus and artery. (d) Inferior pulmonary vein. (e) Subcarinal pocket.

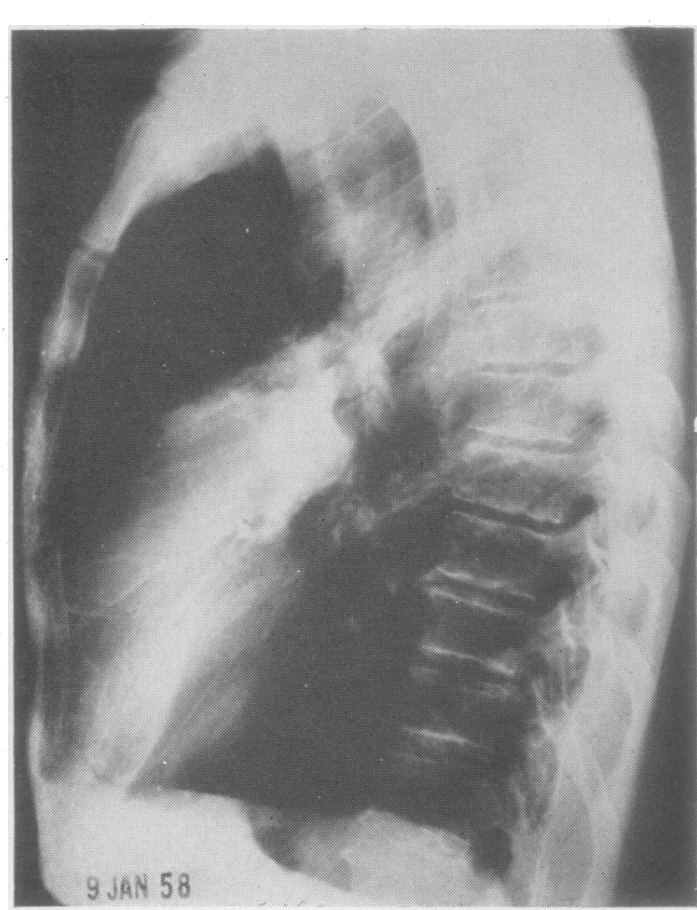

FIG. 1b.-Lateral chest radiograph of the same patient.

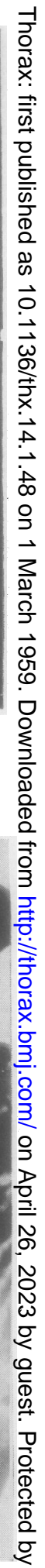

Fig. 3.-Arterial anastomosis completed, the bronchi already having been anastomosed. 
Fig. 4.-Photograph of the left upper lobe, showing sleeves of the bronchus and wall of the pulmonary artery.

involves a certain amount of mobilization of the main hilar structures and also a limited exploration in the fissure.

When it has been decided that a sleeve resection can be carried out, the operation is then proceeded with as far as possible as a block dissection. On the right side the upper lobe vein is ligated, then the vena azygos is divided and the para- and pre-tracheal areas are completely cleared. The arteries to the upper lobe are then secured, and involvement of the main artery assessed so that none, a sector, or a sleeve of this may be removed if required. The right main bronchus is divided flush with the carina, allowing a complete clearance of the subcarinal pocket down behind the left auricle as far as the inferior pulmonary vein. The bronchus is then divided again just above the apical lower and middle lobe bronchi (or below the middle lobe). The portion of main bronchus left behind is carefully inspected to ensure that all growth has been taken away, and if necessary a further portion is removed.

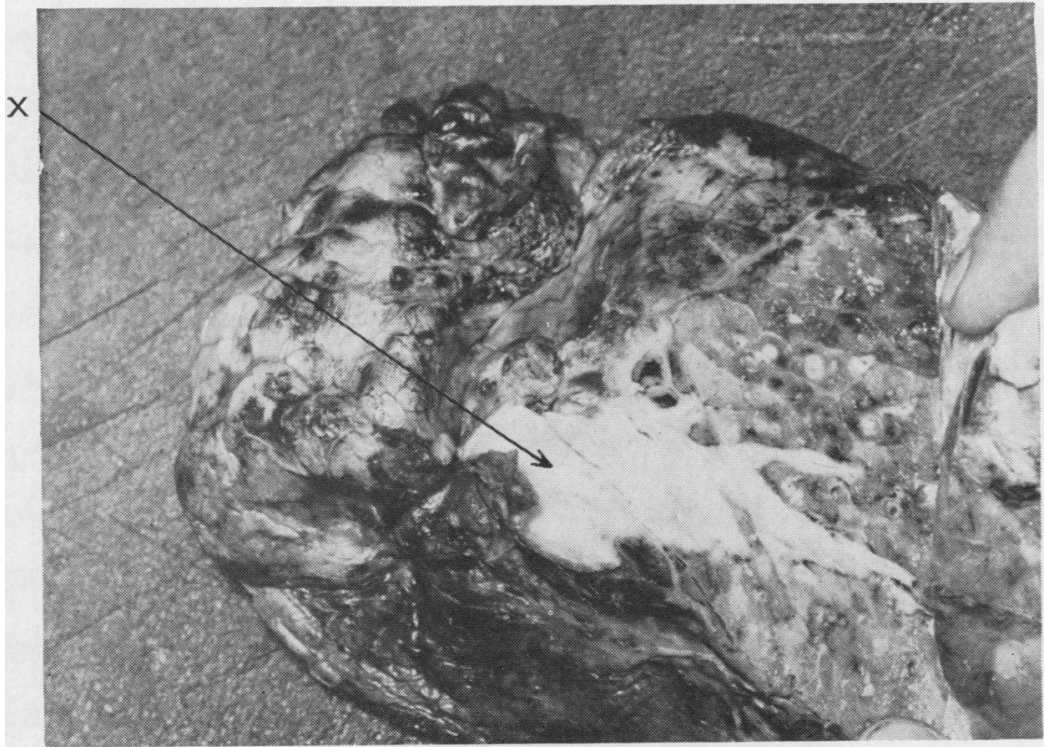

Anastomosis is performed, using interrupted thread sutures with careful coaption of the edges, tying the knots outside. The smaller is adapted to the larger circumference by spacing the sutures. On the left side, the proximal bronchus section is made $2-3 \mathrm{~cm}$. above the upper lobe and the distal section is flush with the apical lower bronchus.

At the end of the dissection, before the anastomosis, the remaining lobe is attached to the mediastinum by the artery and vein which have been stripped bare. In our opinion the clearance of lymph nodes is as complete as in "radical pneumonectomy" except for any perivascular or peribronchial lymphatic spread beyond the distal line of section of the bronchus. According to Nohl (1956) this form of lymphatic spread is infrequent.

Where a sleeve of pulmonary artery has been removed, the arterial anastomosis is completed after $\mathrm{t} \mathrm{h}$ e bronchial anastomosis (see Figs. 1-7).

Finally the development of one-lung anaesthesia

FIG. 5.-Photograph showing involvement of the main bronchus at $X$. 


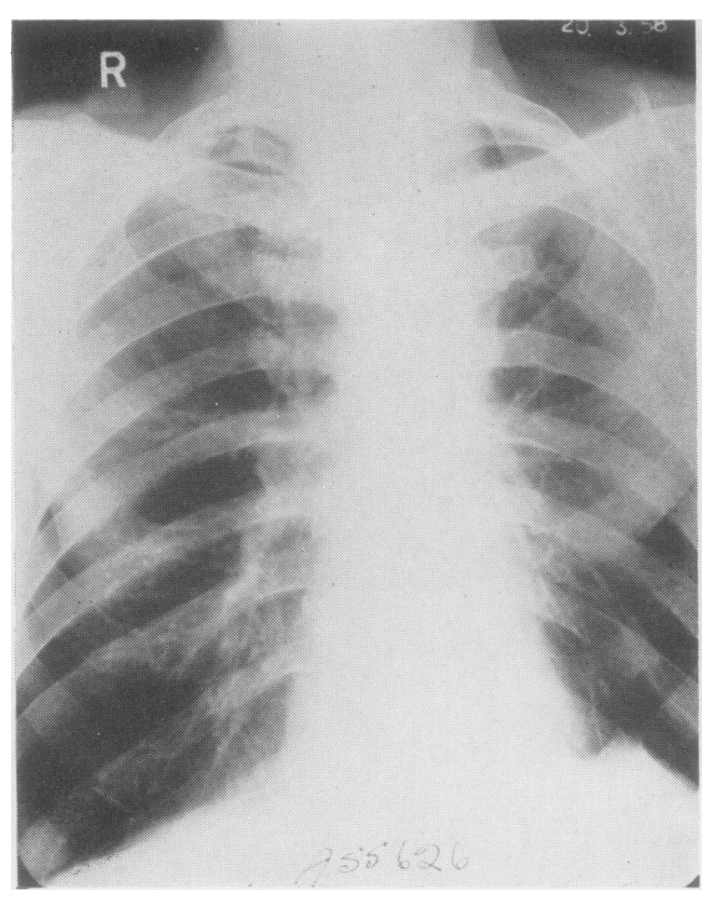

FIG. 6.-Post-operative chest radiograph.

using a Pallister (1957) left endobronchial tube or his modification of the Green tube for the right, has greatly eased the surgeon's problems.

\section{Post-operative Care}

The keynote to a smooth convalescence is attention to detail in the post-operative period. The remaining lung must be fully expanded as the chest is closed. Adequate apical and basal drainage must be provided with wide-bore tubes. From the outset, immediate evacuation of all air and fluid from the chest must be ensured by adequate suction designed to maintain constantly an intrathoracic pressure less than atmospheric. Daily or twice daily radiographs are essential to assess progress, and immediate action must be taken to deal with atelectasis or air or fluid pockets.

\section{OPERATIVE MORTality}

Eight patients died as a direct result of the operation.

One died from intestinal obstruction. This woman, who had previously had a bowel resection for carcinoma, had a palliative sleeve resection of the right upper and middle lobes, and of the pulmonary artery for a metastatic lesion. In spite

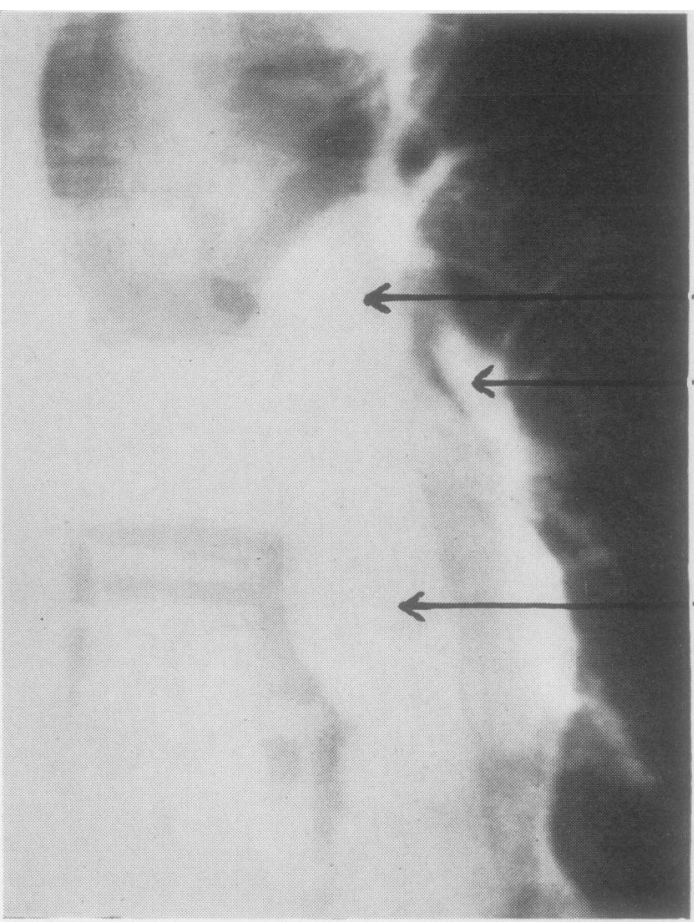

FIG. 7.-Post-operative angiogram, showing patent left pulmonary artery. $a=$ left pulmonary artery. $b=$ left lower lobe artery. $\mathrm{c}=$ common pulmonary trunk.

of the intestinal obstruction being relieved, she died, and at necropsy both anastomoses were intact.

Another patient, who had a left upper lobectomy and sleeve resection of artery and bronchus, died suddenly three hours after the operation for no reason that was apparent at necropsy.

Two patients died of coronary thrombosis, one on the sixth day and the other six weeks after the operation.

Two patients died, one on the third, the other on the fourth post-operative day, from a combination of sputum retention, bronchopneumonia, and respiratory insufficiency.

One patient died from haemoptysis, six weeks after the operation, while receiving radiotherapy. At necropsy there was a communication at the bronchus suture line with the pulmonary artery.

The last patient, who had a sleeve resection of artery and bronchus on the right side, developed thrombosis of the artery, with sloughing of the remaining right lung, and a bronchopleural fistula. In spite of completing the pneumonectomy, the patient died. These are the only instances of fistulae in the series. 
This mortality rate of $8 \%$ is no higher than the mortality rate for lobectomy for carcinoma at the Brompton Hospital. This is in fact $9 \%$ (Cleland, 1958). As the physician has become persuaded that this operation is reasonably safe, he has offered us increasingly poor-risk patients, on whom we would never normally have contemplated surgery.

\section{OTHER COMPLICATIONS}

There have been various non-fatal complications, as shown in Tables III and IV.

\section{TABLE III}

\section{EARLY COMPLICATIONS}

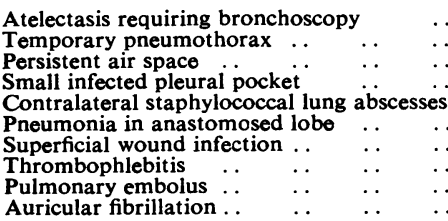

TABLE IV

LATE COMPLICATIONS

Sutures coughed up or removed Granulation tissue polyp at suture line

Haemoptysis due to granulation tissue

Temporary stenosis due to granulation tissue

Other strictures, early or late

\section{PATHOLOGY}

All the specimens were examined histologically, attention being paid to the appearance at the ends of the sleeve. In no instance was it found that the growth had extended to the point of section, and in most instances there was as much as $2 \mathrm{~cm}$. of free bronchus on either side of the growth.

Histologically, the lesions were distributed as shown in Table $\mathrm{V}$.

TABLE V

HISTOLOGICAL TYPE OF LESION

\begin{tabular}{|c|c|c|c|c|c|}
\hline \multicolumn{4}{|c|}{ Type of Lesion } & $\begin{array}{l}\text { No. of } \\
\text { Cases }\end{array}$ & $\begin{array}{l}\text { Hilar Nodes } \\
\text { Involved }\end{array}$ \\
\hline $\begin{array}{l}\text { Squamous . . } \\
\text { Undifferentiated } \\
\text { Adenocarcinoma } \\
\text { Secondary adenoc }\end{array}$ & $\begin{array}{ll}\cdots & \cdots \\
\cdots & \cdots \\
\text { arcinoma }\end{array}$ & $\begin{array}{l}\cdots \\
\cdots \\
\cdots\end{array}$ & $\begin{array}{l}\cdots \\
\cdots \\
\cdots\end{array}$ & $\begin{array}{r}69 \\
15 \\
12 \\
2\end{array}$ & $\begin{array}{r}25 \\
5 \\
2 \\
1\end{array}$ \\
\hline
\end{tabular}

\section{FOLLOW-UP}

The follow-up is short and only provides limited information.

Of the total of 98 patients, 29 are dead. A further five patients of those who are alive are known to have recurrence. Of those who are dead, eight died as a result of the operation, 19 died from recurrence of the carcinoma, and the remaining two patients showed no evidence of carcinoma at necropsy. It was not possible to establish the exact site of recurrence in every instance, but we have positive evidence of the site of recurrence as shown in Table VI.

TABLE VI

SITES OF RECURRENCE

Local recurrence in bronchus Recurrence elsewhere in chest

Supraclavicular node metastases

Distant metastases

\section{SURVIVAL}

Five patients have been operated on more than three years ago and two are alive. Fifteen patients have been operated on more than two years ago but less than three, and of these seven were alive at the end of two years. Sixty-five patients have been operated on more than one year ago, and of these 52 or $80 \%$ were alive at the end of one year. In a personal series of 114 lobectomies for carcinoma Price Thomas (1958) found that $74 \%$ were alive after one year (Table VII).

TABLE VII

SURVIVAL AFTER ONE YEAR COMPARED WITH LOBECTOMY

\begin{tabular}{llll|r|c}
\hline & & & No. & Alive \\
\hline $\begin{array}{l}\text { Sleeve resection } \\
\text { Lobectomy (Price Thomas, } 1958)\end{array}$ & $\ldots$ & $\ldots$ & 65 & $52(80 \%)$ \\
\end{tabular}

\section{CONCLUSION}

There are probably three valid conclusions to be drawn from this experience :

(A) This is a reasonably safe operation to offer to a patient suffering from carcinoma of the bronchus.

(B) The early follow-up results are certainly no worse than the results achieved by conventional treatment.

(C) With this operative technique available, it is now possible to offer surgery to a higher percentage of patients than hitherto.

\section{SUMMARY}

A technique is described for the treatment of patients suffering from carcinoma of the bronchus in whom the physiological reserve would not permit pneumonectomy yet in whom the situation of the growth rendered standard lobectomy inadequate.

A review of 98 patients treated by sleeve resection is presented. 
We wish to express our gratitude to Mr. T. Holmes Sellors and Mr. J. R. Belcher for their constant encouragement and for permission to operate on several of these patients at the country branch of the London Chest Hospital.

\section{REFERENCES}

Allison, P. R. (1956). Personal communication. Bignall, J. R., and Moon, A. J. (1955). Thorax, 10, 183.

Brock, R. C., and Whytehead, L. L. (1955). Brit. J. Surg., 43, 8.
Churchill, E. D., Sweet, R. H., Soutter, L., and Scannell, J. G. (1950) J. thorac. Surg., $20,349$.

Cleland, W. P. (1958). Carcinoma of the Lung, p. 227. E. and S. Livingstone, Edinburgh.

Kirklin, J. W., McDonald, J. R., Clagett, O. T., Moersch, H. J., and Gage, R. P. (1955). Surg. Gyncc. Obstet., 100, 429.

Nohl, H. C. (1956). Thorax, 11, 172. Ochsner, A., Ray, C. J., and Acree, P. W. (1954). Amer. Rev. Tubere., ஹ
70, 763.

Pallister, W. G. (1957). Personal communication.

Thomas, C. Price (1952). Ann. roy. Coll. Surg. Engl., 11, 205.

- (1956). J. roy. Coll. Surg. Edinb., 1, 169.

-.. (1958). Personal communication. 